\title{
The Moonwatch Program: A Model for Amateur Contributions to the ISY
}

\section{James Cornell}

Smithsonian Astrophysical Observatory, Cambridge, MA 02138, U.S.A.

Largely forgotten today is the role that amateur astronomy played in the early days of space exploxation. For example, 1987 is not only the 30 th anniversary of the first artificial satellite but also of history's most successful global organization of amateur astronomers: Moonwatch.

As a worldwide network of volunteer visual observers, Moonwatch was a vital adjunct to Western satellite tracking efforts. In nearly two decades of operation, more than 500 individuals made some 400,000 observations of approximately 6000 objects. Although now only a footnote to space history, Moonwatch suggests that some comparable organization of dedicated and talented amateurs might contribute to the International Space Year of 1992.

Moonwatch resulted from the International Geophysical Year of 1957-58. Fred L. Whipple, director of the Smithsonian Astrophysical Observatory, had earlier accepted United States responsibility for the optical tracking of any satellites launched during that 18-month period. As his primary instrument, he proposed a fast, large-aperture Schmidt camera called the Baker-Nunn. Eventually, 12 cameras would be located around the world.

Whipple also suggested establishing a volunteer network of observers to locate satellites visually and provide the basic data required for more precise optical tracking. A worldwide appeal for "Visual Observers of Satellites" was published in the July 1956 Sky and Telescope and planetarium director Armand Spitz personally contacted many astronomy groups. Response was immediate: some 1500 volunteers were recruited in the United States alone within the first few months.

In the spring of 1957, Smithsonian set up a professional steering committee chaired by George Van Biesbroeck, then of Yerkes Observatory. By that summer, after a series of test alerts proved a visual system could effectively track satellites, Moonwatch had 80 teams in the United States, 30 in Japan, 10 in both A rgentina and Germany, and 33 more distributed over another 15 nations.

Typically, a Moonwatch team would set up a "fence" of observers using several wideangle telescopes trained on the meridian at different altitudes. When an observer at one "picket" saw a satellite cross the meridian (defined by a cross bar on a vertical pole), he signaled the team's timekeeper, thus obtaining a fix on the object. The leader would then relay the information to the Smithsonian. 
The basic Moonwatch telescope was of rugged, simple design with a $50 \mathrm{~mm}$ objective, a $180 \mathrm{~mm}$ focal length; and a 6.8 -degree field of view. The optics were mounted in an 8.5 -inch aluminum tube. The 6-power instrument could show objects down to 8 th magnitude and the wide field increased the chances of finding a satellite even when its orbit was not well known.

The establishment of Moonwatch was done in an atmosphere of some urgency, since both the United States and the Soviet Union were on the verge of launching satellites. Indeed, when Sputnik I was launched on October 4, Moonwatch was one of the few Western organizations ready to provide tracking data. The first confirmed sightings came October 8 from teams in Sydney and Woomera, Australia; the first American observations came two nights after that.

During the initial weeks of the Space Age, essentially all observational data outside the Soviet Union came from Moonwatch. Eventually, Moonwatch would make 700 observations of Sputnik and its third-stage rocket. And, by the end of the first full year, volunteers had amassed nearly 7000 visual observations of the first seven satellites.

When IGY ended, both Moonwatch and Baker-Nunn networks continued under the Smithsonian with support from NASA. Naturally, the increasing precision of other groundbased systems significantly changed Moonwatch objectives. For example, Moonwatch was particularly well-suited for observing low-perigee objects and for tracking reentering satellites. The most spectacular success occurred in September 1962, when Moonwatchers observed the reentry of Sputnik 4 over the midwestern United States and subsequently recovered a 20-pound chunk of debris.

Although originally intended to operate for only 18 months, Moonwatch provided data for over 18 years, being disbanded finally in 1975. Most extraordinary was the dedication and persistence of Moonwatch members over those nearly two decades. They performed an arduous and time-consuming task with little reward beyond the knowledge that they were aiding international space goals. Moonwatch demonstrated well what amateurs could do when properly inspired and led.

On a practical level, Moonwatch was extremely cost-effective: producing nearly a halfmillion observations worth more than $\$ 14$ million. Less tangible, but equally important, Moonwatch made significant contributions to the public understanding of science, especially in those hectic, and for some people, quite alarming, days of Sputnik. Also, many younger members, introduced to space science in this direct way, went on to pursue careers in astronomy, astrophysics, and related fields. And perhaps more than any other effort, Moonwatch served to underscore the truly international nature of space research.

These three contributions of Moonwatch - public information, science education, and worldwide understanding - are important considerations for any comparable amateur program mounted in the International Space Year of 1992. 